\title{
Voltage Stability Analysis of a Multiple-Infeed Load Center Using Phasor Measurement Data
}

\author{
Mostafa Parniani, Joe H. Chow, Luigi Vanfretti, Bharat Bhargava, and Armando Salazar
}

\begin{abstract}
Voltage stability is a security concern for modern power systems. It can be analyzed using detailed or equivalent models. In this paper a new approach is presented for voltage stability analysis using synchronized phasor measurement data. Simple equivalent models of the interconnected system and load side at a measurement point are estimated from the data, and then used for calculating PV curves and predicting the stability limit. Two different models are proposed, and compared based on the analyses performed on the event recordings from US Western Power System. Minimal modeling and formulation makes the method suitable for online calculations. The models are continuously updated to reflect the effects of different system components and changes.
\end{abstract}

Index Terms-Voltage Stability, Synchronized Phasor Measurement Unit, Security Analysis, Model Estimation, Load Modeling.

\section{INTRODUCTION}

Y YNCHRONIZED phasor measurements refer to timetagged high-sampling rate voltage and current measurements from power stations, most likely at highvoltage transmission levels, using GPS clocks. The US Western Power System already has a network of phasor measurement units (PMUs) with continuous recording to capture disturbance events [1]. Since the August 14, 2003 Northeast Blackout, the Eastern Interconnection Phasor Project has been formed to initiate the installation of a similar network of PMUs in the US Eastern Interconnected Power System [2]. PMU data provide a suitable platform to monitor system security. Potential applications of PMU data, including contingency analysis, model validation, dynamic analysis and control are already discussed in the literature [3]-[5].

Voltage stability is a security concern for modern power systems. Both static and dynamic analyses are used to investigate different aspects of voltage instability phenomena [6],[7]. The problem can be studied using detailed or equivalent models [8]. In this paper, a new approach is presented for voltage stability analysis using synchronized

M. Parniani is with the Department of Electrical Engineering, Sharif University of Technology, Tehran, Iran. He is now a visiting scholar a Rensselaer Polytechnic Institute (RPI), Troy, NY. Email: parniani@sharif.edu

J.H. Chow is with the Department of Electrical, Computer, and Systems Engineering, RPI, Troy, NY. Email: chowj@rpi.edu

L. Vanfretti is with the Department of Electrical, Computer, and Systems Engineering, RPI, Troy, NY. Email: vanfrl@rpi.edu

B. Bhargava and A. Salazar are with Southern California Edison, Rosemead, CA 91770. phasor measurement data. Simple equivalent models of the interconnected system and load side at a measurement point are estimated from the data, and then used for calculating PV curves and predicting the stability limit. Two different models are proposed, and compared based on the analyses performed on the event recordings from US Western Power System. Minimal modeling and formulation makes the method suitable for online calculations. The models are continually updated to reflect the effects of various system components and changes.

\section{PROBLEM STATEMENT AND MODELING APPROACH}

Given the PMU data for a bus or line terminal, we are interested in predicting voltage stability margin for power transfer through that bus or line. Measured data include voltage and current phasors at a high sampling rate. Active and reactive powers are readily calculated from voltage and current values.

It is intended that relatively simple models be estimated from measurement data, and be used for the analyses. Knowledge of the system configuration and detailed model of the interconnected system is not to be used. This makes the method applicable to the new environment of restructured power systems. As the operating conditions of the system change continuously, model parameters are also subject to change. It is possible, however, to update the parameters using measurement data acquired with a fairly low sampling rate.

In the following sections, two different methods are presented and examined through case studies. The first one is a single voltage-source thevenin equivalent for the $\mathrm{HV}$ network, together with an appropriate load-side model. The second model is two back-to-back thevenin equivalents for either of the incoming and outgoing sides.

\section{A. Single voltage source model}

In many cases, power is imported from the interconnected HV system to a load area. In other words, the HV system is sitting in one side of the PMU location, and the load area on the other. To calculate the power-voltage characteristics at the bus of interest, appropriate models are needed for both sides.

Let us consider thevenin equivalent for the system as viewed the point of PMU measurement. Figure 1 shows a single line diagram of the system. Due to the nature of EHV systems, network resistance is neglected. Though it is straightforward to extend the results with the equivalent resistance included. In this figure, 


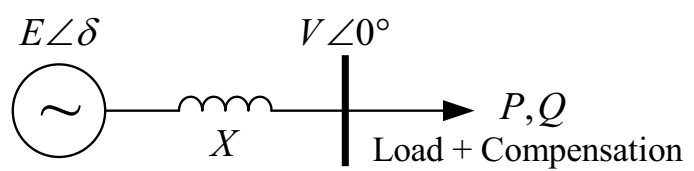

Fig. 1. Equivalent model for the system side.

$$
\begin{gathered}
P=\frac{E V}{X} \sin \delta \\
Q=\frac{V(E \cos \delta-V)}{X}
\end{gathered}
$$

Taking the last $\mathrm{m}$ samples for any instant of time yields:

$$
\begin{gathered}
P_{i} X-V_{i} E \sin \delta_{i}=0 \quad i=1, \ldots, m \\
Q_{i} X-V_{i} E \cos \delta_{i}+V_{i}^{2}=0
\end{gathered}
$$

With $2 \mathrm{~m}$ equations in (3) and (4), only $\mathrm{m}+2$ variables, i.e. $\mathrm{E}, \mathrm{X}$ and $\delta_{i}, i=1, \ldots, m$ are unknown. They are hence overdetermined, and need to be calculated using the following least square errors optimization.

$$
\underset{E, X, \delta_{i}}{\operatorname{Min}_{1}}\left\|\begin{array}{c}
P_{1} X-V_{1} E \sin \delta_{1} \\
Q_{1} X-V_{1} E \cos \delta_{1}+V_{1}^{2} \\
\vdots \\
P_{m} X-V_{i} E \sin \delta_{m} \\
Q_{m} X-V_{m} E \cos \delta_{m}+V_{m}^{2}
\end{array}\right\|
$$

\section{B. Load-Side Model}

Various static and dynamic load models have been presented in the literature [9-11]. Constant power factor and nonlinear static [7] models are among the commonly used basic models. However, examination of some measured data reveals that none of the above is a good representation of the aggregate load area. One reason is that the local network includes automatically controlled reactive compensators and voltage regulating devices, which are not modeled separately.

Measured PQ curves like the one shown in Fig. 6 suggest a fairly linear relation between active and reactive powers.

$$
Q=\alpha+\beta P
$$

One might note that the constant power factor load is a special case of the above model. Besides, in (6) slope of the characteristic could be negative. This is the fact in the case studies presented later in this paper. In that case, reactive power absorption drops as the active power rises.

Using the same data samples as for the system model estimation, $\alpha$ and $\beta$ are the solution of the following linear least square problem.

$$
\underset{\alpha, \beta}{\operatorname{Min}}\left\|\left[\begin{array}{cc}
1 & P_{1} \\
\vdots \\
1 & P_{m}
\end{array}\right]\left[\begin{array}{l}
\alpha \\
\beta
\end{array}\right]-\left[\begin{array}{c}
Q_{1} \\
\vdots \\
Q_{m}
\end{array}\right]\right\|
$$

The single voltage source model of Fig. 1 can then be combined with the linear P-Q load side model to calculate the
PV characteristic and voltage stability limit for power transfer through the study point. From (1), (2) and (6)

$$
P^{2} X^{2}-E^{2} V^{2}+\left(\alpha X+\beta P X+V^{2}\right)^{2}=0
$$

\section{Double Voltage Source Model}

With a PMU measuring the voltage and currents at an EHV line terminal, both of the incoming and outgoing sides are likely to have voltage support. In other words, not always the outgoing power is delivered to a load area without active voltage regulation. A typical example is shown in Fig. 2.

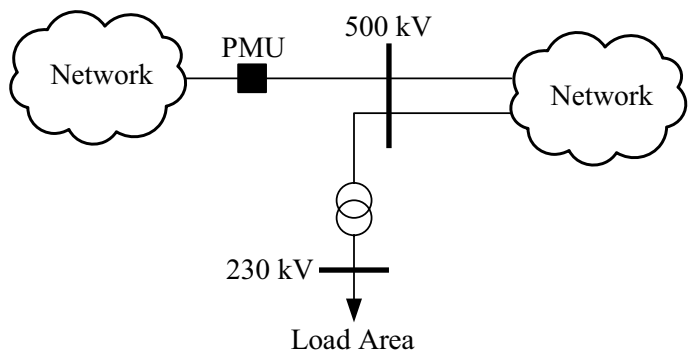

Fig. 2. A typical system layout at the point of phasor measurement.

Although the linear P-Q model implicitly allows for the above situation, a more accurate model is to use thevenin equivalents for both sides (Fig. 3). For such model to represent loads as well as the network, equivalent resistances should not be ignored.

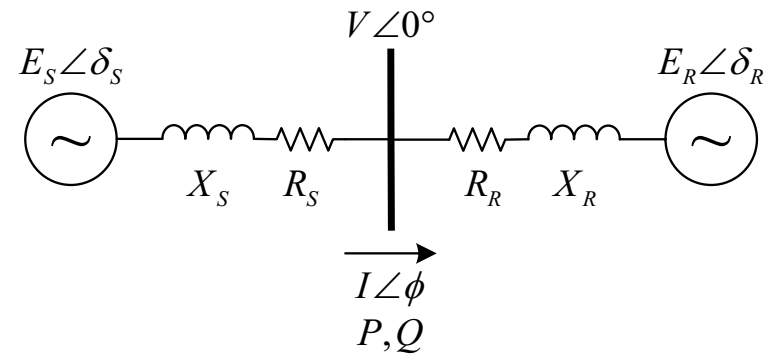

Fig. 3. Double voltage source model.

Any operating point in any time is the intersection of the VI characteristics at the two sides. This is illustrated graphically in Fig. 4. So, having several operating points measured, we can identify model parameters of both sides. The overall PV characteristic and stability limit are then calculated without the assumptions like constant power factor or even linear P-Q loading. From Fig. 3,

$$
\begin{aligned}
& E_{s} \angle \delta_{s}-\left(R_{s}+j X_{s}\right) I \angle \phi=V \\
& E_{r} \angle \delta_{r}+\left(R_{r}+j X_{r}\right) I \angle \phi=V
\end{aligned}
$$

The bus voltage is arbitrarily chosen as the phase reference. Separating the real and imaginary parts of (9) and (10) yields:

$$
\begin{aligned}
& E_{s} \cos \delta_{s}-R_{s} I \cos \phi+X_{s} I \sin \phi=V \\
& E_{s} \sin \delta_{s}-R_{s} I \sin \phi-X_{s} I \cos \phi=0 \\
& E_{r} \cos \delta_{r}+R_{r} I \cos \phi-X_{r} I \sin \phi=V \\
& E_{r} \sin \delta_{r}+R_{r} I \sin \phi+X_{r} I \cos \phi=0
\end{aligned}
$$




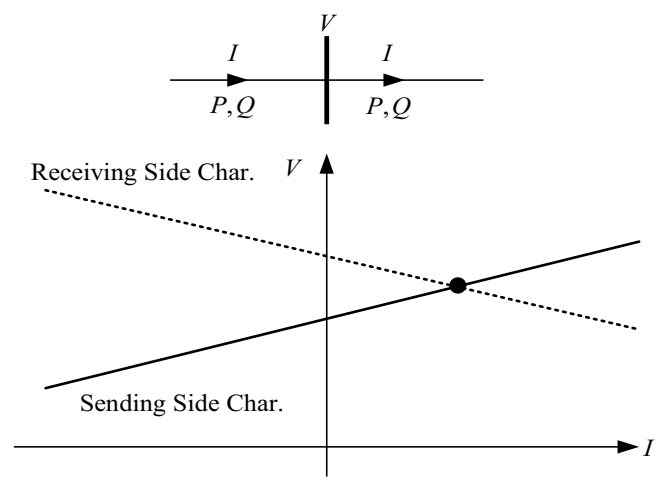

Fig. 4. The operating point is intersection of the sending side and receiving side characteristics.

The unknown variables and parameters in (11) to (14) are $\mathrm{E}_{\mathrm{s}}, \delta_{s}, \mathrm{R}_{\mathrm{s}}, \mathrm{X}_{\mathrm{s}}, \mathrm{E}_{\mathrm{r}}, \delta_{r}, \mathrm{R}_{\mathrm{r}}$ and $\mathrm{X}_{\mathrm{r}}$. Only three samples are sufficient to solve the set of equations for these parameters. For more accurate identification of the model using $m$ samples ( $m \geq 3$ ), the following least square errors optimization is to be solved.

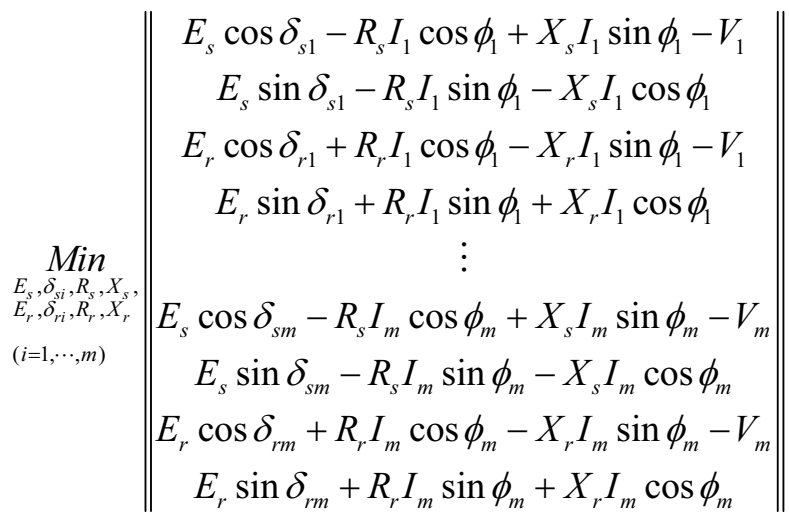

Equations (11) to (15) may also be written in terms of $\mathrm{P}$ and $Q$ rather than I and $\phi$. Simply substitute $I \cos \phi=P / V$ and $I \sin \phi=-Q / V$.

Once the model parameters are known, the PV characteristic at the point of PMU measurement can be calculated as follows. According to Fig. 3,

$$
\begin{gathered}
P-j Q=V \hat{I}=V\left(\frac{E_{s} \angle \delta_{s}-E_{r} \angle \delta_{r}}{Z \angle \theta}\right) \\
V=E_{s} \angle \delta_{s}-Z_{s} \angle \theta_{s} \cdot \hat{I}
\end{gathered}
$$

where

$$
\begin{gathered}
Z \angle \theta=\left(R_{s}+R_{r}\right)+j\left(X_{s}+X_{r}\right) \\
Z_{s} \angle \theta_{s}=R_{s}+j X_{s}
\end{gathered}
$$

The real and imaginary parts of (16) and (17) can be separated and solved with different values of $\delta_{s}$.

It is noteworthy that PMU data are collected at a high sampling rate, e.g. $30 \mathrm{samples} / \mathrm{s}$. Model parameter estimation need not be that fast. Instead, it is important to determine how long time period is sufficient for identification. During steady state, changes in power flow are fairly slow. So, using highrate samples within a short period of time results in very close data points, and hence less observability and less accurate estimation. The results presented in this paper are calculated with 1 sample per 5 seconds to capture the changes in parameters following a major disturbance. Longer intervals are recommended for the cases that voltage stability calculations are intended for tens of minutes or hours ahead.

\section{CASE STUDY}

To demonstrate the modeling and analysis approach presented in the previous section, we use the PMU measurements taken from a $500 \mathrm{kV}$ power transfer path in the US Western Power System to predict the stability limit for power transfer through that path.

The proposed methodology is applicable to continuously monitor the system security during normal as well as transient conditions. To illustrate this, the analyses are carried out on the recordings of two different disturbances affecting the transfer path. For each event, calculations are separately performed at three periods: the pre-disturbance condition, transient period following the onset of disturbance, and the quasi stationary post-disturbance condition. The impact of disturbance on the equivalent model parameters and the voltage stability limit is then investigated. All active and reactive powers reported in this section are normalized to the nominal flow of the transfer path.

Figure 5 shows the active and reactive power variations during the first event, occurred during 2000.
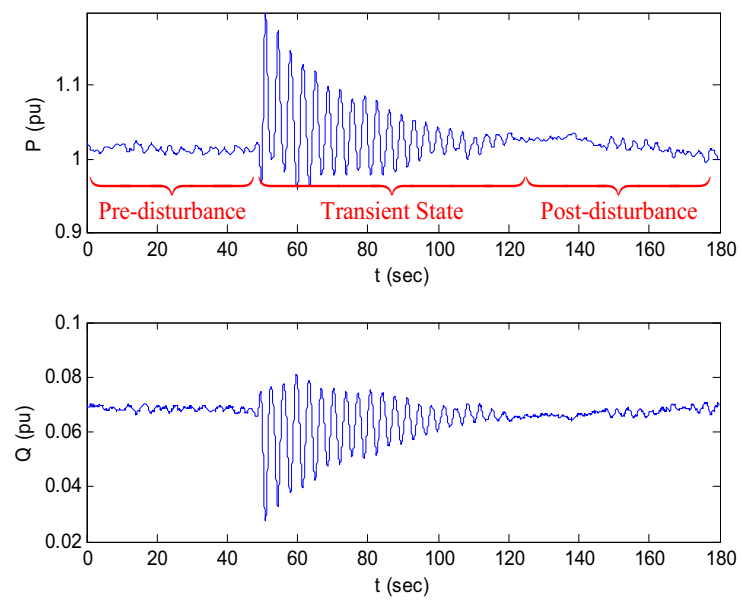

Fig. 5. PMU recordings of a disturbance in 2000.

Figure 6 depicts the measured P-Q characteristic during the same event. As mentioned earlier, although the receiving side in this example is a large load area, this characteristic does not exhibit a constant power factor trait. Instead, the P-Q relation is seemingly linear, with a negative slope. 


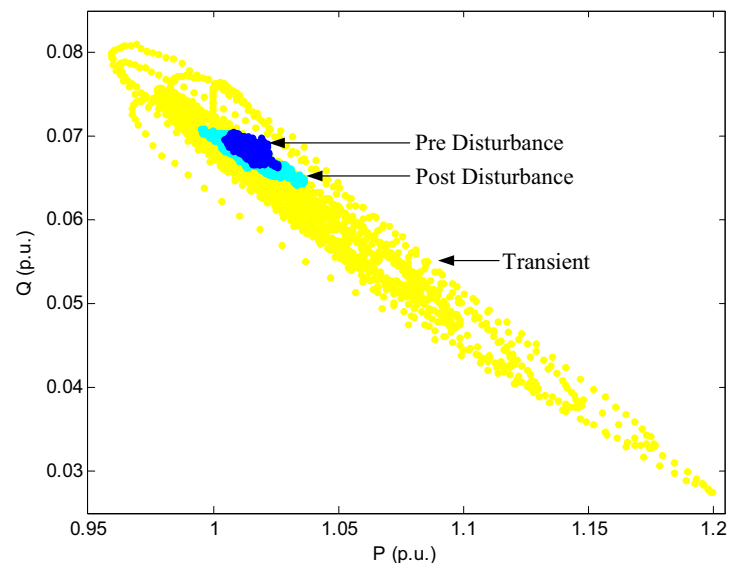

Fig. 6. The measured P-Q characteristic during the 2000 disturbance.

To model the system, for each of the three periods, data samples with 5 seconds interval were used to identify the relevant model parameters. With the single voltage source (SVS) model, the equivalent voltage and reactance are calculated for the network side, and $\alpha$ and $\beta$ for the load side. Table I shows the identified parameters. The estimated load side models are also shown in Fig. 7 together with the identification data in the corresponding period.

It is noteworthy that the equivalent reactance for transient period is considerably less than those of pre-disturbance and post-disturbance conditions. This is consistent with the fact that transient reactances of generators are much less than their synchronous reactances.

The equivalent reactance for quasi-stationary postdisturbance condition is very close to its pre-disturbance counterpart. The change in the equivalent reactance of the system from one steady state condition to another is a potential measure to recognize a change in the system configuration at some location not too far from the PMU installation point.
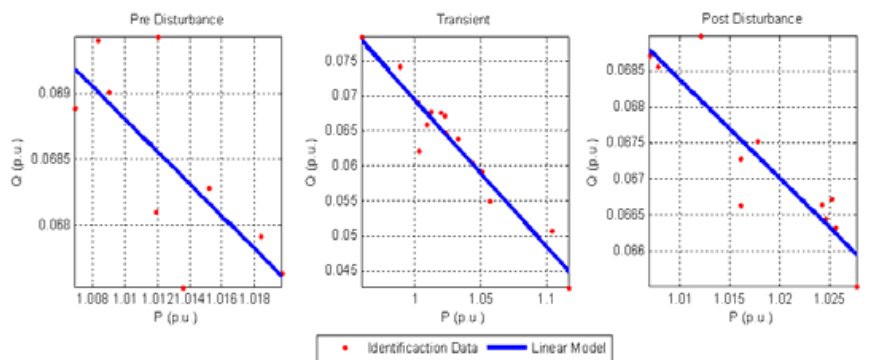

Fig. 7. Load side model estimation for the conditions before, during, and after the 2000 disturbance.

TABLE I

MODEL PARAMETERS AT DIFFERENT PERIODS, 2000 CASE

\begin{tabular}{|c|c|c|c|c|}
\hline $\begin{array}{c}\text { System } \\
\text { Condition }\end{array}$ & $\begin{array}{c}\mathrm{E}_{\mathrm{s}} \\
(\mathrm{pu})\end{array}$ & $\begin{array}{c}\mathrm{X}_{\mathrm{s}} \\
(\mathrm{pu})\end{array}$ & $\alpha$ & $\beta$ \\
\hline Pre-disturbance & 1.164 & 0.0227 & 3.8656 & -0.12324 \\
\hline Transient & 1.102 & 0.0145 & 5.5727 & -0.20948 \\
\hline Post-disturbance & 1.163 & 0.0225 & 4.2717 & -0.14367 \\
\hline
\end{tabular}

Figure 8 depicts the estimated PV curves for the above three conditions. Also shown in this figure are the measured data points during each period. Due to the lower reactance during transient period, maximum power transfer capability in this condition is considerably higher than the other two conditions. This means that voltage stability is not a major concern during large transients, whereas the angular stability is. The steady state power transfer limits observed in Fig. 8 are consistent with the values calculated by detailed power flow simulations.

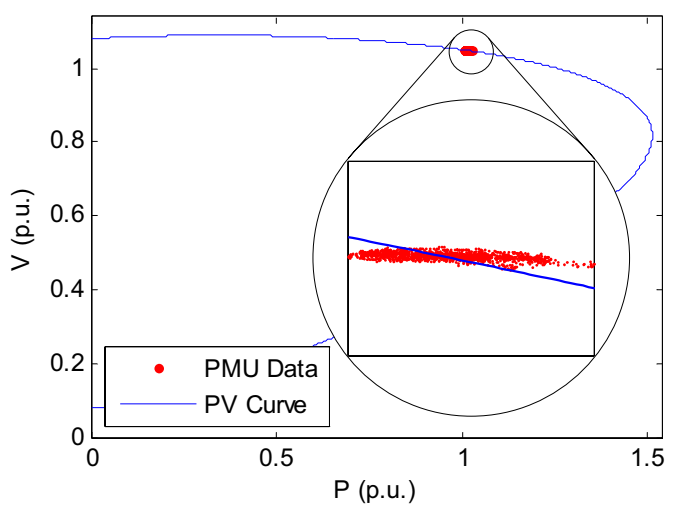

a) Pre-disturbance condition

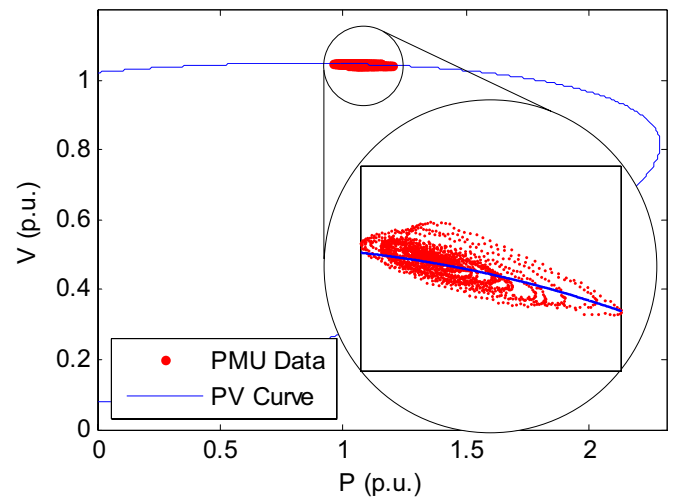

b) Transient period

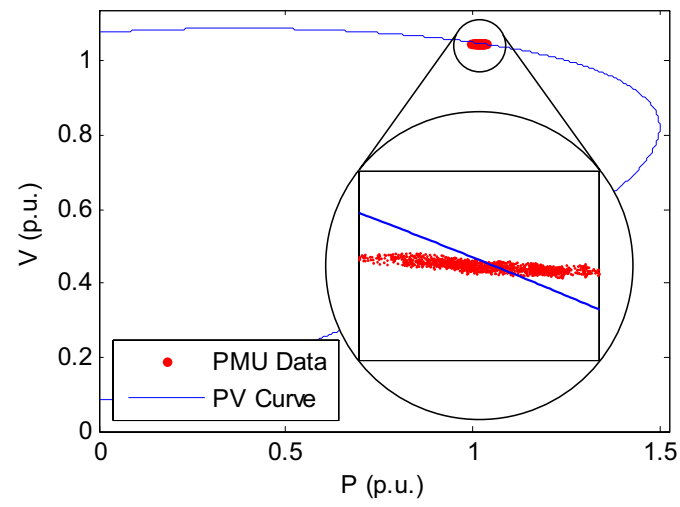

c) Post-disturbance quasi-stationary condition

Fig. 8. PV curves calculated with the single voltage source model, together with the measured data during the 2000 event. 


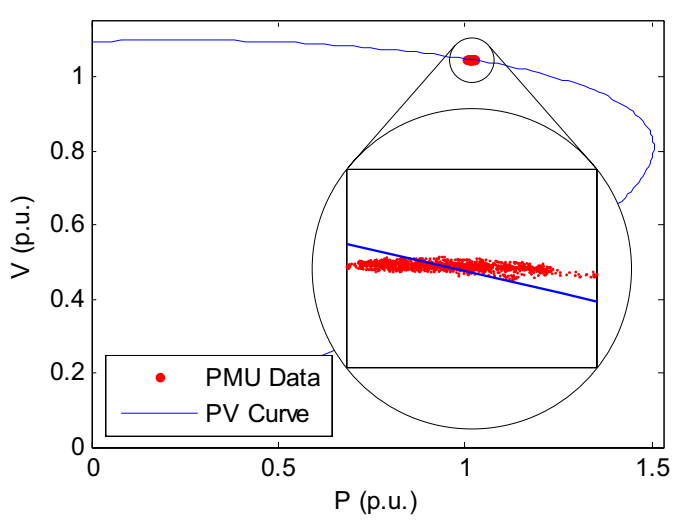

a) Pre-disturbance condition

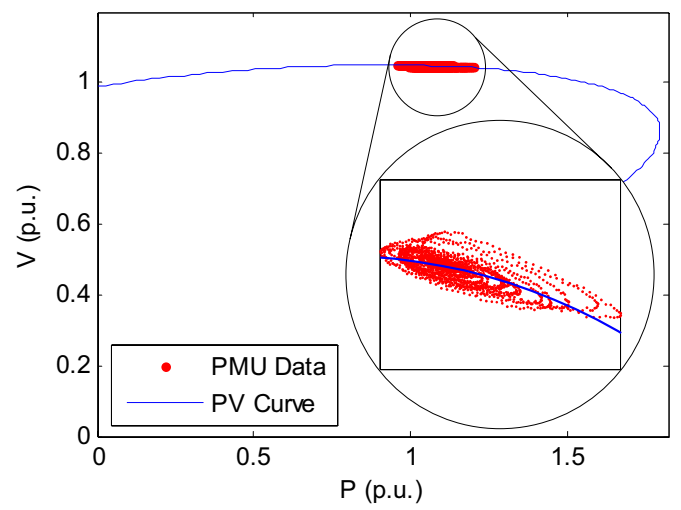

b) Transient period

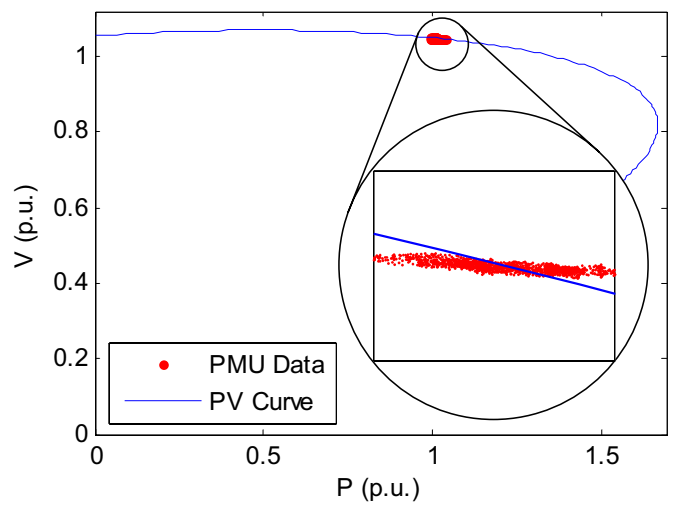

c) Post-disturbance condition
Next, we analyze the same case using the double voltage source (DVS) model. The identified model parameters are given in Table II. This table also includes a summary of results with both models and for the other event discussed later. Figure 9 shows the PV curves obtained with the DVS model. In this case too, the transient period exhibits higher voltage stability limit, and the pre-disturbance and steady post-disturbance conditions have relatively close characteristics.

To explore further on the consistency of analysis results obtained with the proposed methodology, we investigate another event recorded during 2002 at the same location. Figures 10 and 11 show the measured active and reactive power variations and $\mathrm{P}-\mathrm{Q}$ characteristic during that event. A similar trend in the P-Q relation as before is evident in this case too.
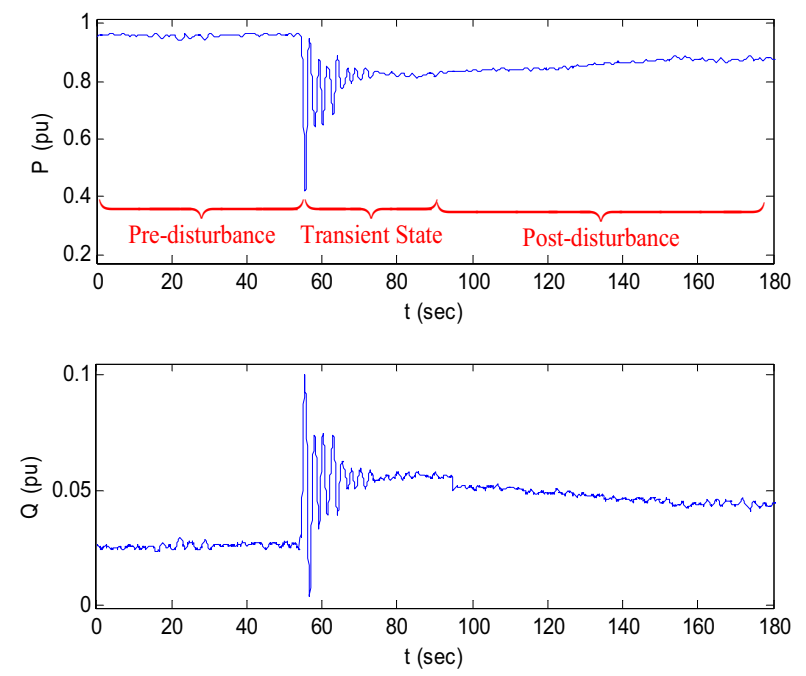

Fig. 10. PMU recordings of an event in 2002.

Fig. 9. PV characteristics obtained with the DVS model, 2000 case.

TABLE II

SUMMARY OF RESULTS FOR THE TWO EVENTS AND WITH THE TWO DIFFERENT MODELING APPROACHS

\begin{tabular}{|c|c|c|c|c|c|c|c|c|c|}
\hline \multirow{2}{*}{\multicolumn{2}{|c|}{ System Condition }} & \multicolumn{3}{|c|}{ Single voltage source model } & \multicolumn{5}{|c|}{ Double voltage source model } \\
\hline & & $\mathrm{E}_{\mathrm{s}}$ & $\mathrm{X}_{\mathrm{s}}$ & $\mathrm{P}_{\max }$ & $E_{s}$ & $\mathrm{X}_{\mathrm{s}}$ & $\mathrm{E}_{\mathrm{r}}$ & $\mathrm{X}_{\mathrm{r}}$ & $\mathrm{P}_{\max }$ \\
\hline \multirow{3}{*}{2000} & Pre-disturbance & 1.164 & 0.0227 & 1.45 & 1.101 & 0.0217 & 1.094 & 0.0217 & 1.50 \\
\hline & Transient & 1.102 & 0.0145 & 2.29 & 1.097 & 0.0205 & 0.942 & 0.0142 & 1.94 \\
\hline & Post-disturbance & 1.163 & 0.0225 & 1.50 & 1.094 & 0.0214 & 1.038 & 0.0191 & 1.63 \\
\hline \multirow{3}{*}{2002} & Pre-disturbance & 1.142 & 0.0237 & 1.40 & 1.104 & 0.0232 & 1.103 & 0.0233 & 1.39 \\
\hline & Transient & 1.078 & 0.0123 & 2.51 & 1.078 & 0.0264 & 0.950 & 0.0196 & 1.49 \\
\hline & Post-disturbance & 1.152 & 0.0261 & 1.30 & 1.092 & 0.0256 & 0.980 & 0.0197 & 1.47 \\
\hline
\end{tabular}




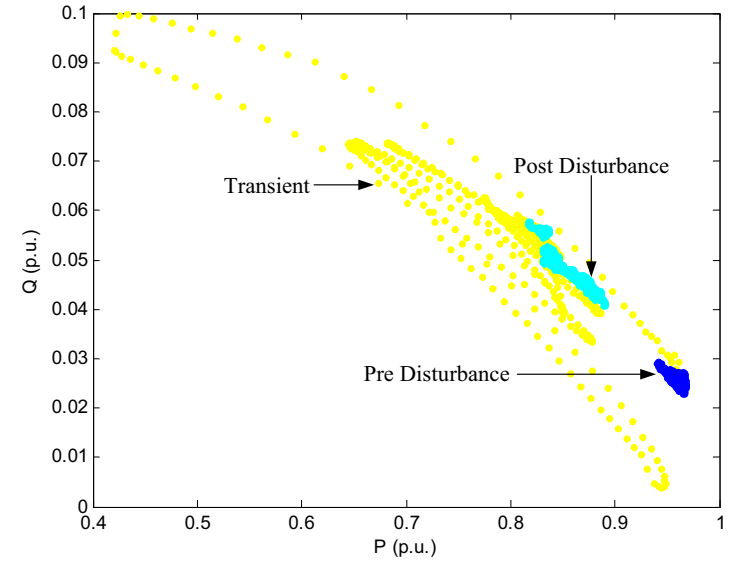

Fig. 11. The measured P-Q characteristic during the 2002 disturbance.

Model parameters with both the SVS and DVS models are calculated and shown in Table II. Figures 12 and 13 illustrate the calculated PV curves for different periods, using the two models correspondingly. Also in this case, the transient period shows lower equivalent reactances and higher power transfer limit. In both cases, however, the results obtained with DVS model demonstrate a milder jump during transients. Besides, there is a slight difference between the values calculated with the two models for the post-disturbance condition. These differences could be attributed to the linearity constraint of load side model, and the measure of data fitness to this constraint. Further cases are under investigation to determine the accuracy of results obtained with each model.

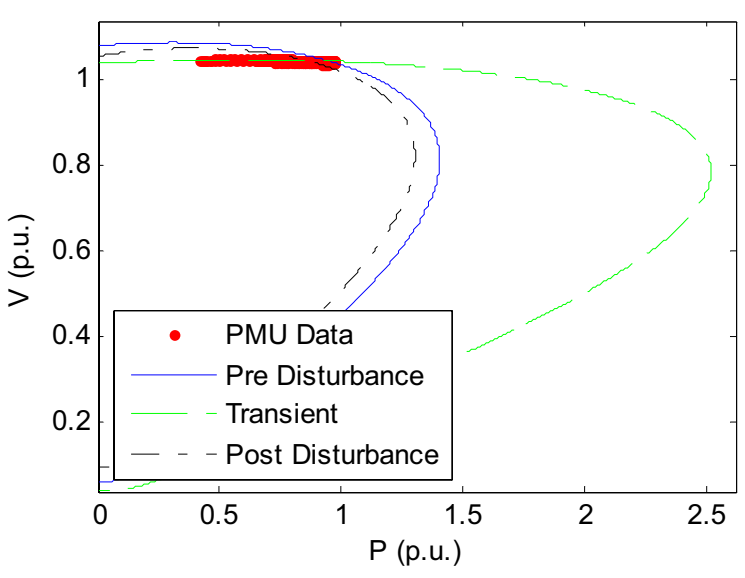

Fig. 12. PV characteristics obtained with the SVS model, 2002 case.

\section{CONCLUSIONS}

In this paper, a new approach was presented for voltage stability analysis using synchronized phasor measurement data. Simple equivalent models of the interconnected system and load side at a measurement point are estimated from the data, and then used for calculating PV curves and predicting the stability limit. Two different models were proposed, and compared based on the analyses performed on the event recordings from US Western Power System. Minimal modeling makes both methods suitable for online calculations. The models are continuously updated to reflect the effects of different system components and changes.

The first method comprises a thevenin equivalent of the system side, together with a linear P-Q load side model. This model can implicitly account for the controlled compensators and voltage regulating devices present in the load side. This model is expected to yield sufficiently accurate results as long as the linearity constrant is satisfied. The second model consists of two thevenin equivalents for either sides of the measurement point. Thus, it represents the active voltage support at both sides of the PMU explicitly, and does not impose the P-Q linearity constraint.

The proposed methods can be employed to monitor voltage stability in a transfer path during steady state as well as transients conditions. Also, the changes in the equivalent reactance and stability limit, from pre-disturbance condition to the steady state post-disturbance condition, can be used to identify nearby alterations in the system configuration following the disturbance.

Case studies show that during transients, equivalent reactances decrease. The phenomenon can be well explained due to the lower reactances of synchronous machines during transients. Consequently, voltage stability limit tends to be higher during transients.

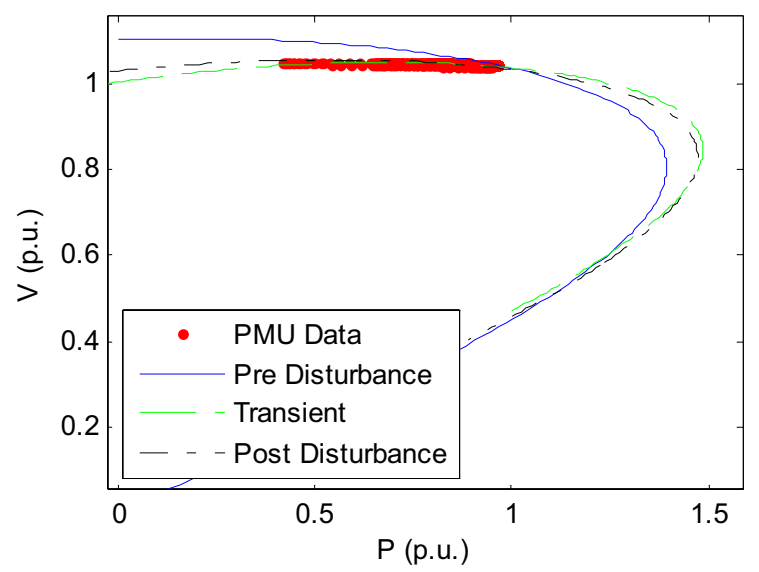

Fig. 13. PV characteristics obtained with the DVS model, 2002 case.

\section{REFERENCES}

[1] J. Hauer, D. Trudnowski, G. Rogers, B. Mittelstadt, W. Litzenberger, and J. Johnson, "Keeping an eye on power system dynamics," IEEE Computer Applications in Power, vol. 10, pp. 50-54, Oct. 1997.

[2] Eastern Interconnect Phasor Project [Online]. Available: http://phasors.pnl.gov/

[3] D. N. Kosterev, C. W. Taylor, W. A. Mittelstadt, "Model validation for the August 10, 1996 WSCC system outage," IEEE Transactions on Power Systems, vol. 14, pp. 967-979, 1999.

[4] J. F. Hauer, "Application of Prony analysis to the determination of modal content and equivalent models for measured power system response," IEEE Transactions on Power Systems, vol. 6, pp. 1062-1068, Aug. 1991.

[5] D. N. Kosterev, J. Esztergalyos, and C. A. Stigers, "Feasibility study of using synchronized phasor measurements for generator dropping controls in Colstrip system," IEEE Transactions on Power Systems, vol. 13, no. 3, pp. 755-761, Aug. 1998. 
[6] T. Van Cutsem, C. Vournas, Voltage Stability of Electric Power Systems, Kluwer Academic Publishers, 1998.

[7] P. Kundur, Power System Stability and Control, McGraw Hill, 1994.

[8] D.E. Julian, R.P. Schulz, K.T. Vu, W.H. Quaintance, N.B. Bhatt, D. Novosel, "Quantifying proximity to voltage collapse using the Voltage Instability Predictor (VIP)," IEEE Power Engineering Society Summer Meeting, 2000, vol. 2, pp. 931-936.

[9] W.W. Price, K.A. Wirgau, J.V. Mitsche, "Load Modeling for power flow and transient stability computer studies," IEEE Transaction on Power Systems, Vol. 3, No. 1, pp. 180-187, Feb. 1988.

[10] E. Vaahedi, H.M.Z. El-Din, W.W. Price, "Dynamic Load modeling in large scale stability studies," IEEE Transactions on Power Systems, Vol. 3, No. 3, pp. 1039-1045, Aug. 1988.

[11] W.W. Price, S.G. Casper, C.O. Nwankpa, R.W. Bradish, H-D. Chiang, C. Concordia, J.V. Staron, C.W. Taylor, E. Vaahedi, G. Wu, "Bibliography on load models for power flow and dynamic performance simulation," IEEE Transactions on Power Systems, Vol. 10, No. 1, pp. 523-538, Feb. 1995.

\section{BIOGRAPHIES}

Mostafa Parniani (Senior Member, IEEE) received his B.Sc. degree from Amirkabir University of Technology in 1987, and the M.Sc. degree from Sharif University of Technology (SUT) in 1989, both in Electrical Power Engineering. He worked for Ghods-Niroo Consulting Engineers Co. and for Electric Power Research Center in Tehran during 1988-90. He obtained the $\mathrm{Ph} . \mathrm{D}$. degree in Electrical Engineering from the University of Toronto, Canada, in 1995. Then, he joined the EE Dept. of SUT as an assistant professor. He is currently a visiting scholar at Rensselaer Polytechnic Institute, USA. His research interests include power system dynamics and control, and Flexible AC transmission Systems (FACTS).

Joe H. Chow (Fellow, IEEE) received his $\mathrm{PhD}$ in Electrical Engineering from the University of Illinois, Urbana-Champaign. He worked in the power system business in General Electric Company before joining Rensselaer Polytechnic Institute in 1987. He was the Acting Chair of ECSE Dept. in 1999 and 2000, after which he spent a sabbatical at the New York Independent System Operator. He is the Associate Dean of Engineering for Research and Graduate Programs. His research interests include power system dynamics and modeling, Flexible AC Transmission System Controllers, power markets, and large-scale multivariable control systems.

Luigi Vanfretti (Member, IEEE) is a Master's student in the Electrical, Computer, and Systems Engineering Department at Rensselaer Polytechnic Institute, Troy, NY. He received his B.S.E.E. degree from the San Carlos University of Guatemala in June 2005. During fall 2005 he was a Visiting Academic at the Department of Electronics and Electrical Engineering of The University of Glasgow, Scotland. His research interests are stability, control and security of electric power systems.

Bharat Bhargava is a Consulting Engineer in the Technology Integration group of Transmission and Distribution Business Unit of Southern California Edison Company in Rosemead, California, where he has worked for the last twenty-six years. He is actively involved in phasor measurements, transient analysis of power system, SSR studies, System Dynamics studies, Power Quality, Railway Electrification, capacitor switching, and Insulation Coordination studies. He graduated from Delhi University in 1961 with a Masters from Rensselaer Polytechnic Institute in 1976. He worked with the UP State Electricity Board in India from 1961 to 1975 . Mr. Bhargava is a Senior Member of PAS, IAS Communication and Vehicular Societies of IEEE and a Member of CIGRE.

Armando Salazar (Member, IEEE) is a research engineer in the Engineering Advancement Group of Southern California Edison (SCE) working in the Synchronized Phasor Measurement System project. He received his Electrical Engineering degree in Power Systems from the National University of Colombia. Before joining Edison, he was an Energy Consultant in South America. For 6 years, he worked for the Latin American Energy Organization (OLADE). He also worked for the Bogotá Power Company (EEB). Currently he is pursuing his Master degree in Power Systems at Kansas State University (KSU). He is a registered professional Electrical Engineer in the State of California. 